\title{
Mechanism of Procedural Failure Related to Wingspan
}

\author{
Lin-Bo Zhao, MD', ${ }^{1}$, Soonchan Park, MD', Donggeun Lee, MD', \\ Deok Hee Lee, MD'1, Dae Chul Suh, MD¹
}

Purpose: Wingspan is the only FDA approved self-expanding stent for intracranial artery and known to have better delivery compared to balloon expandable stent. However, some delivery failure has been reported but incidence and mechanism of the failure have not been completely elucidated. We present the cause and mechanism of Wingspan deployment failure experienced in our Institute.

Materials and Methods: We experienced deployment failure in seven patients (8.8\%) out of 80 patients who underwent Wingspan stenting since 2007. Mean age of the patients was 62 (range 47 78) and male to female ratio was $6: 1$. We evaluated the cause and mechanism why the deployment was not successful and how we could manage it subsequently.

Results: We categorized failures occurred in seven patients into three categories: delivery failure $(n=3)$, deployment failure of stent $(n=3)$, retrieval failure of dual tapered (olive) tip of the inner body through the deployed the stent $(n=1)$. The technical failure in using Wingspan stent (delivery, deployment and retrieval failures) are related to tortuousness of the proximal $(n=4)$ as well as distal $(n=1)$ cerebral vessels to the stenotic lesion and bulky profile of the olive tip $(n=2)$.

Conclusion: The technical failure in using Wingspan stent (delivery, deployment and retrieval failures) are related to tortuousness of the proximal as well as distal cerebral vessels to the stenotic lesion and bulky profile of the olive tip. To avoid device-related complication, complete understanding of the stent design is mandatory before using the stent.

Key Words : Intracranial stenting; Atherosclerosis; Self-expanding stent

'Departments of Radiology and Research Institute of Radiology, University of Ulsan, College of Medicine, Asan Medical Center, Seoul, Korea

${ }^{2}$ Department of Radiology, First Affiliated Hospital of Nanjing Medical University, Nanjing, China

Received April 13, 2012; accepted after revision June 28, 2012.

Correspondence to: Dae Chul Suh, MD, Department of Radiology, University of Ulsan, College of Medicine, Asan Medical Center, 88, Olympic-ro 43-gil, Songpa-gu, Seoul 138-736, Korea.

Tel. 82.2.3010.4366 Fax. 82.2.476.0090

E-mail: dcsuh@amc.seoul.kr

This is an Open Access article distributed under the terms of the Creative Commons Attribution Non-Commercial License (http://creativecommons.org/licenses/by-nc/3.0) which permits unrestricted non-commercial use, distribution, and reproduction in any medium, provided the original work is properly cited.
Manifestation of atherosclerosis is known to be various according to ethnic difference [1-6]. Atherosclerotic intracranial stenosis is more common in Koreans than western countries [5]. Bare metal stent for coronary artery has been used effectively in Korea, although the stent was only used as an investigational purpose in the United States [3, 7-10].

The only stent approved by the Food and Drug Administration for the treatment of intracranial atherosclerotic disease is the self-expanding Wingspan stent system (Stryker, Kalamazoo, MI, USA). It has been available since 2005 for the treatment of patients with 50 to $99 \%$ stenosis who had had a transient ischemic 


\section{Wingspan Deployment Failure}

attack or stroke while receiving antithrombotic therapy [11]. It has also been used in stent-assisted coil embolization for aneurysms in case of atherosclerotic narrow of parent arteries [12].

Although some delivery failure has been reported (Table 1), there were few literatures to introduce failure rate of the Wingspan stent deployment and the mechanism of the failure [13-18]. We report deployment failure of Wingspan stent in our experiences and present mechanism of the failure and how to manage the failure.

\section{MATERIALS AND METHODS}

The database of neurointervention in Asan Medical Center (AMC) was reviewed retrospectively to identify all Wingspan stent procedures which were used for the treatment of intracranial atherosclerotic disease. Records were reviewed to identify cases of failure of stent deployment in daily practice.

Since 2007, 80 Wingspan stents were placed in our department for the treatment of intracranial atherosclerotic arterial stenosis. Procedural details are the same as those described previously [3, 7-9, 19]. Among 80 patients, we identified seven instances $(8.8 \%)$ of failure of stent deployment (Table 1). Mean age of the patients was 62 (range 47 78) and male to female ratio was 6:1.

We excluded a patient because Wingspan was used for an aneurysm coil embolization. In this patient, Wingspan was inappropriately deployed proximal to the target lesion while treating a wide-necked paraclinoid internal carotid artery (ICA) aneurysm with atherosclerotic change in parent artery. A Neuroform
Ez (Stryker, Kalamazoo, MI, USA) was used for stentassisted coil embolization after the Wingspan stent was removed by a snare loop device successfully.

We defined procedural failure as failure of any process in Wingspan stent insertion, delivery failure as failed delivery of Wingspan system into proper position for stenotic lesion, deployment failure as failed deployment of stent despite proper positioning of Wingspan system, and retrieval failure as failed retrieval of dual tapered (olive) tip after deployment of the stent because of the friction between stent strut and bulky olive tip.

\section{Wingspan Delivery System}

Wingspan delivery system consists of inner and outer bodies, and nitinol (Wingspan) stent. When the delivery system is introducing, a olive tip protrudes distal to the outer body which has outer diameter of 3.5F. Dual tapered tip has $9 \mathrm{~mm}$ length, entry profile of 0.027 and mid-profile of $0.046 \mathrm{inch}$. When the stent is being deployed, outer body is pulling back while maintaining the inner body in its own position. After deployment, dual tapered tip is retrieved by pulling the delivery system through the deployed stent.

\section{RESULTS}

We categorized procedural failures occurred in seven patients into three categories (Table 2): delivery failure of the system $(n=3)$, deployment failure of stent $(n=$ 3 ), retrieval failure of olive tip of the inner body through the deployed the stent $(n=1)$.

\section{Delivery Failure}

Table 1. Literature Review of Cases of Wingspan Stent Deployment Failure

\begin{tabular}{|c|c|c|c|c|}
\hline Author & Year & No. of Cases & Technique failure & Results \\
\hline Chiam [13] & 2008 & 2 & $\begin{array}{l}\text { Wingsapan stents could not be delivered to the occlusive } \\
\text { site because of excessive vascular tortuosity }\end{array}$ & $\begin{array}{l}\text { Both changed to } \\
\text { Enterprise }\end{array}$ \\
\hline Costalat [14] & 2011 & 1 & Stent incomplete opening inside the ICA & No complications \\
\hline Fiorella [15] & 2007 & 1 & $\begin{array}{l}\text { A tortuous carotid anatomy precluded delivery of the } \\
\text { Wingspan stent }\end{array}$ & $\begin{array}{l}\text { Underwent stenting with } \\
\text { Wingspan lately }\end{array}$ \\
\hline Levy [16] & 2009 & 2 & $\begin{array}{l}\text { Excessively tortuous cerebrovasculature that would not } \\
\text { allow tracking of the Wingspan System to the occlusion }\end{array}$ & $\begin{array}{l}\text { Both changed to } \\
\text { enterprise }\end{array}$ \\
\hline Zaidat [17] & 2008 & 1 & $\begin{array}{l}\text { Wingspan stent could not track beyond the middle } \\
\text { cerebral artery/ICA junction }\end{array}$ & $\begin{array}{l}\text { Deployed in the } \\
\text { proximal clot }\end{array}$ \\
\hline Lee [18] & 2009 & 4 & $\begin{array}{l}\text { Excessive tortuous carotid siphon precluded delivery of } \\
\text { the stent to the lesion, in one case, the other } 3 \text { cases } \\
\text { misplaced the stents }\end{array}$ & $\begin{array}{l}\text { Two cases of additional } \\
\text { stent placement }\end{array}$ \\
\hline
\end{tabular}

Abbreviations: ICA, internal carotid artery 


\section{Lin-Bo Zhao, et al.}

There were three patients in whom delivery of the delivery system to the lesion has failed. In patient 1 , while treating a serious stenosis at right M1-M2 junction, successful balloon angioplasty was performed but the Wingspan stent delivery system could not be introduced to the lesion because of excessive vascular tortuousness. We failed to deploy the stent despite multiple attempts. In patient 2 , we could not advance the stent delivery system to the target lesion beyond the tight carotid siphon even after using stiff guide wire while treating a focal severe stenosis at middle portion of left middle cerebral artery trunk. A Neuroform stent then was used as a substitute after balloon angioplasty. Patient 3 revealed a severe stenosis of the right $\mathrm{M} 1$ segment just distal to the previously stented area by bare metal stent in which there was no restenosis. The olive tip of the delivery system could not introduce beyond the previous stent after balloon angioplasty. Then an Enterprise was used to relieve the stenosis.

\section{Deployment Failure}

As in three patients of our experience, there seemed to be different mechanism of deployment failure. In patient 4, the angiogram showed complete occlusion of the distal left M1. The stent was not deployed even though the stent delivery system was in proper position to cover the lesion. We removed the whole system because there was too much resistance felt in the outer body, which was not pulling back smoothly. After removal of the stent, we found that there was partially deployed stent at the tip (Fig. 1). This configuration revealed that the acute angulation between M1-2 segment prevented continuous and smooth deployment of the stent. Finally, we introduce an Enterprise and could open the occluded segment. In patient 5 , stent delivery system was finally advanced to the basilar artery through excessively tortuous right subclavian artery and vertebral artery, but the stent could not be deployed because the stabilizer was not as stiff as to provide enough supporting force. Then we had to try another Wingspan stent and made the success finally. As to patient 6, stent could not be deployed at the proper position because of marked resistance between inner and outer bodies caused by excessive proximal vascular tortuousness, even the olive tip of the delivery system had navigated over the lesion. We tried to advance the stent by pushing the inner body but finally failed to push the stent segment because olive tip at the end of the inner body was stretched out from the end of the outer body (Fig. 2). When the delivery system was withdrawn, we found that the stretched portion of the inner body was exposed far beyond the stent loaded

Table 2. Case Summary of Wingspan Stent Deployment Failure in AMC

\begin{tabular}{|c|c|c|c|c|c|c|c|}
\hline Case & $\begin{array}{l}\text { Age/ } \\
\text { Gender }\end{array}$ & $\begin{array}{l}\text { Symptoms } \\
\text { and signs }\end{array}$ & Clinical type & Lesion & $\begin{array}{l}\text { Wingspan } \\
\text { diameter } \times \\
\text { length }(\mathrm{mm})\end{array}$ & Technique failure & Management \\
\hline 1 & 78/M & $\begin{array}{l}\text { Hemiparesis, } \\
\text { dysarthria }\end{array}$ & $\begin{array}{l}\text { progressive } \\
\text { stroke }\end{array}$ & Right M1 & $3.0 \times 15$ & $\begin{array}{l}\text { Delivery failure due to } \\
\text { vascular tortuousness }\end{array}$ & Failed stenting \\
\hline 2 & $51 / \mathrm{M}$ & $\begin{array}{l}\text { Hemiparesis } \\
\text { Stroke }\end{array}$ & infarction & Left M1 & - & $\begin{array}{l}\text { Delivery failure due to } \\
\text { tight carotid siphon }\end{array}$ & $\begin{array}{l}\text { Changed to } \\
\text { Neuroform } 3.0 \times 15\end{array}$ \\
\hline 3 & $47 / M$ & $\begin{array}{l}\text { Hemi-numbness } \\
\text { TIA at } 4 y \text { after stenting }\end{array}$ & $\begin{array}{l}\text { restenosis of } \\
\text { stent }\end{array}$ & Right M1 & $3.0 \times 15$ & $\begin{array}{l}\text { Delivery failure beyond } \\
\text { stenting site and stenosis }\end{array}$ & $\begin{array}{l}\text { Changed to } \\
\text { Enterprise } 4.5 \times 22\end{array}$ \\
\hline 4 & $70 / \mathrm{M}$ & $\begin{array}{l}\text { Dysarthria, } \\
\text { hemiparesis } \\
\text { Stroke }\end{array}$ & $\begin{array}{l}\text { progressive } \\
\text { stroke }\end{array}$ & $\begin{array}{l}\text { Left M1 } \\
\text { occlusion }\end{array}$ & $3.0 \times 15$ & $\begin{array}{l}\text { Deployment failure of } \\
\text { stent due to angled } \\
\text { vessel distal to lesion }\end{array}$ & $\begin{array}{l}\text { Changed to } \\
\text { Enterprise } \\
4.5 \times 22\end{array}$ \\
\hline 5 & $56 / M$ & $\begin{array}{l}\text { Paresis } \\
\text { Stroke }\end{array}$ & infarction & $\begin{array}{l}\text { VBJ } \\
\text { occlusion }\end{array}$ & $3.0 \times 20$ & $\begin{array}{l}\text { Deployment failure due to } \\
\text { insufficient inner body } \\
\text { support }\end{array}$ & $\begin{array}{l}\text { Changed to } \\
\text { another Wingspan } \\
4.0 \times 20\end{array}$ \\
\hline 6 & $70 / F$ & Hemiparesis & $\begin{array}{l}\text { progressive } \\
\text { stroke }\end{array}$ & Left M1 & $3.0 \times 9$ & $\begin{array}{l}\text { Deployment failure due to } \\
\text { vascular tortuousness }\end{array}$ & $\begin{array}{l}\text { Changed to Driver } \\
2.5 \times 8\end{array}$ \\
\hline 7 & $64 / M$ & $\begin{array}{l}\text { Hemiparesis } \\
\text { Stroke }\end{array}$ & infarction & $\begin{array}{l}\text { Right M1 } \\
\text { occlusion }\end{array}$ & $3.0 \times 15$ & $\begin{array}{l}\text { Retrieval failure of Olive } \\
\text { tip trapped in deployed } \\
\text { stent }\end{array}$ & $\begin{array}{l}\text { Resheathing the } \\
\text { olive tip by outer } \\
\text { body }\end{array}$ \\
\hline
\end{tabular}

Abbreviations: $\mathrm{TIA}$, transitional ischemic attack, VBJ = vertebrobasilar junction 


\section{Wingspan Deployment Failure}

segment in the delivery microcatheter (outer body).

\section{Retrieval Failure of the Dual Tapered (Olive) Tip}

As in patient 7, after successful deployment of Wingspan stent, we met a little resistance when we tried to retrieve the olive tip of the stent delivery system. The outer body was readvanced through the deployed stent and then the olive tip was retrieved and repositioned to the distal end of the microcatheter (outer body). Reducing the size gap between olive tip and inner body shaft can make better smooth retrieval of the delivery system.

\section{DISCUSSION}

The published data on the use of the Wingspan stent for intracranial atherosclerosis revealed that technical success rate was high between $96.7 \%$ and $98.8 \%$ [15, $17,18,20]$. When we review the literature, there were only few publications regarding Wingspan deployment failure [13-17] being totally less than one dozen of cases. We reported seven cases of Wingspan stent deployment failures in our experience and revealed $7.5 \%$ failure rate except the last patient in whom stent deployment was finally successful.

The overall rate of technical failure in our study
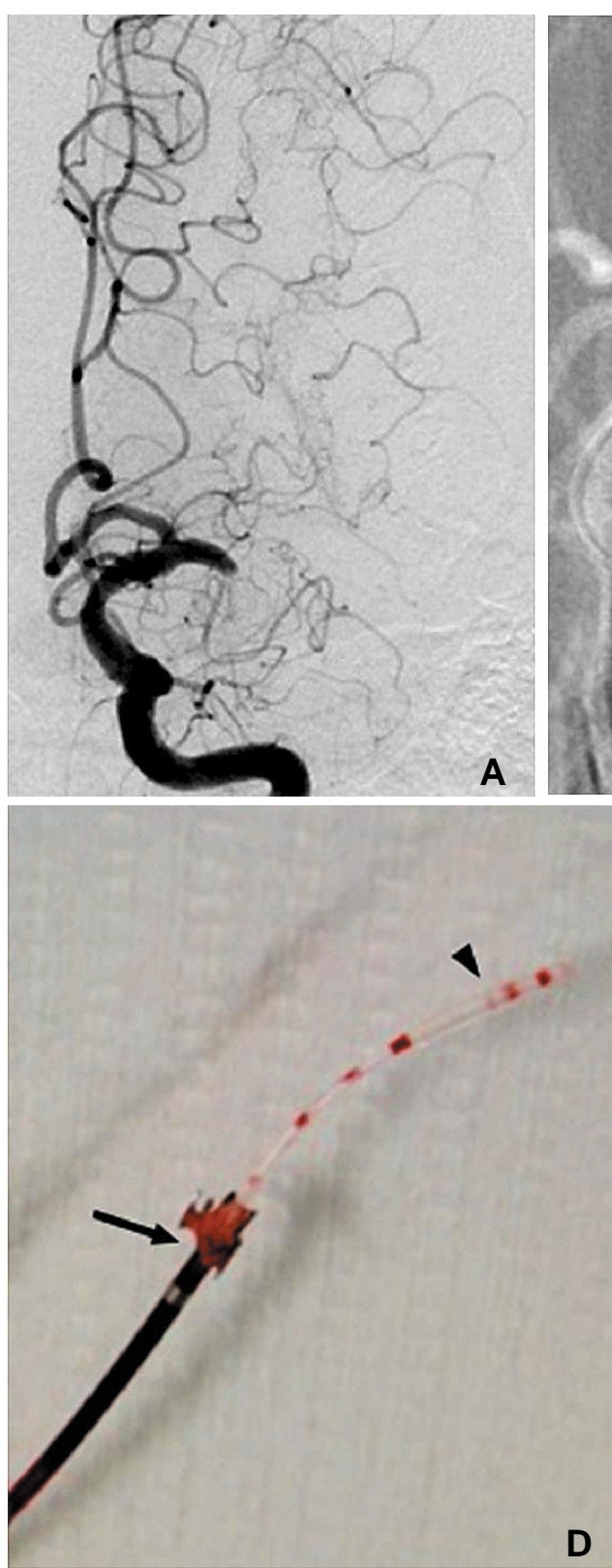
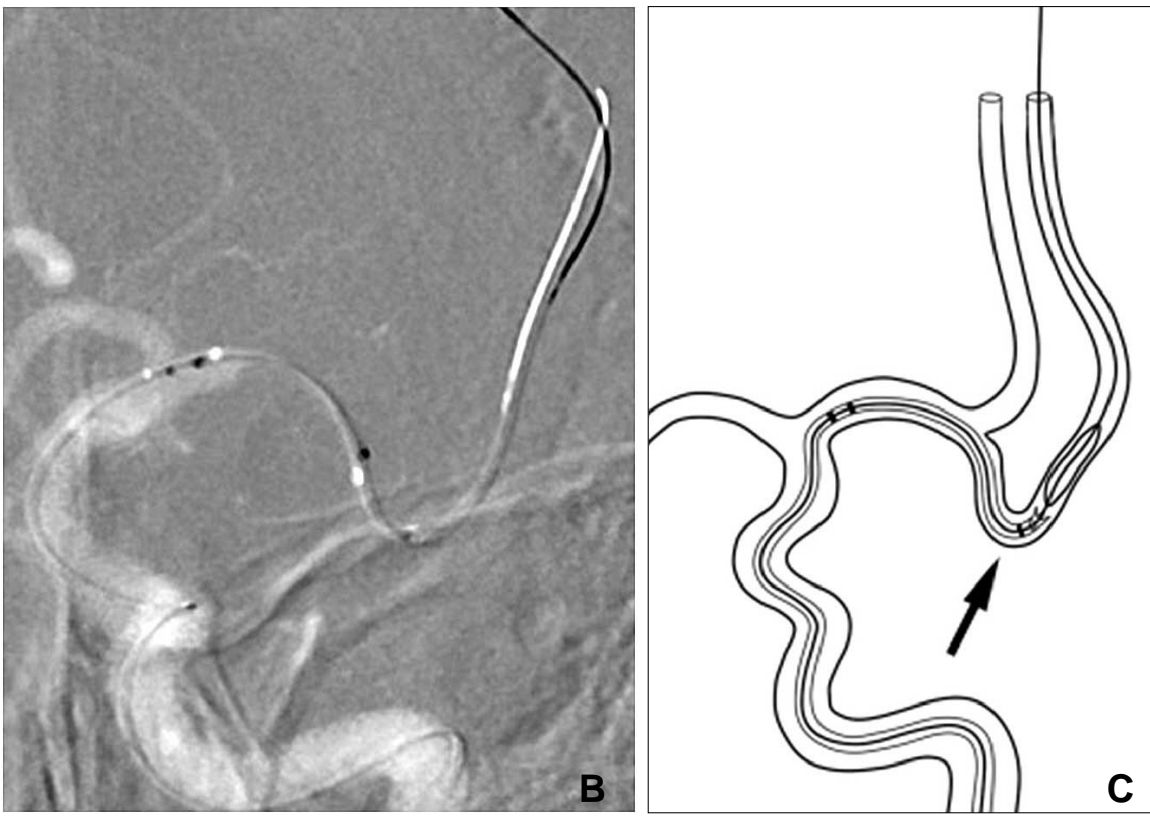

Fig. 1. A 70-year-old male patient presented with dysarthria and hemiparesis due to left M1 occlusion.

A, B. Wingsspan delivery system was introduced into the occluded left middle cerebral artery (MCA). However, outer body could not been pulled back to deploy the stent because there was excessive resistance between inner and outer body of the delivery system.

C. Diagram shows the mechanism when and how the deployment failure happened. Note an acute angled bending of the inferior division of M2 (arrow).

D. Removed system showed that partially deployed the stent tip (arrow) in between outer body and stretched dual tapered (olive) tip (arrowhead).

E. Final angiogram shows rather good filling of the MCA branches after deployment of an Enterprize stent. 
seems to be higher than other studies. This difference may reveal that the failure rate can be underestimated because information regarding stent deployment failure is not exactly reported. The other possible reason is that some studies did not include stent misplacement as technical failure [18].

The main cause of Wingspan stent delivery failures in the published studies was excessive cerebral vascular tortuousness [21]. There were several reported cases of Wingspan delivery failure because of excessively tortuous cerebrovasculature [13, 15-17]. Among them, a patient presented later with recurrent stenosis and successfully underwent stenting with Wingspan [15].

Although vascular tortuousness was the delivery failure reason as in two out of three delivery failure patients, we experienced in a patient whom the olive tip of the stent could not pass the lesion beyond the previously stented M1. This passage failure of the olive tip is due to 0.046 inch $(1.17 \mathrm{~mm})$ mid-profile of the olive tip could not pass the rigid tube of previous bare metal stent as in patient 3 .

The salvage technique for the delivery failure is to resort to stent with more flexible delivery system and thinner profile, such as Enterprise and Neuroform. Such self-expanding stents designed for coiling of wide-neck aneurysm sometimes neither have proper size of stent length and diameter nor enough radial force to resist delayed restenosis in atherosclerotic lesions. Lesley et al. [22] introduced a catheter exchange technique for the Wingspan stent deployment by cutting off the olive tip of the delivery system if the delivery system could not be advanced to the lesion. This concept is similar to use Neuroform except that
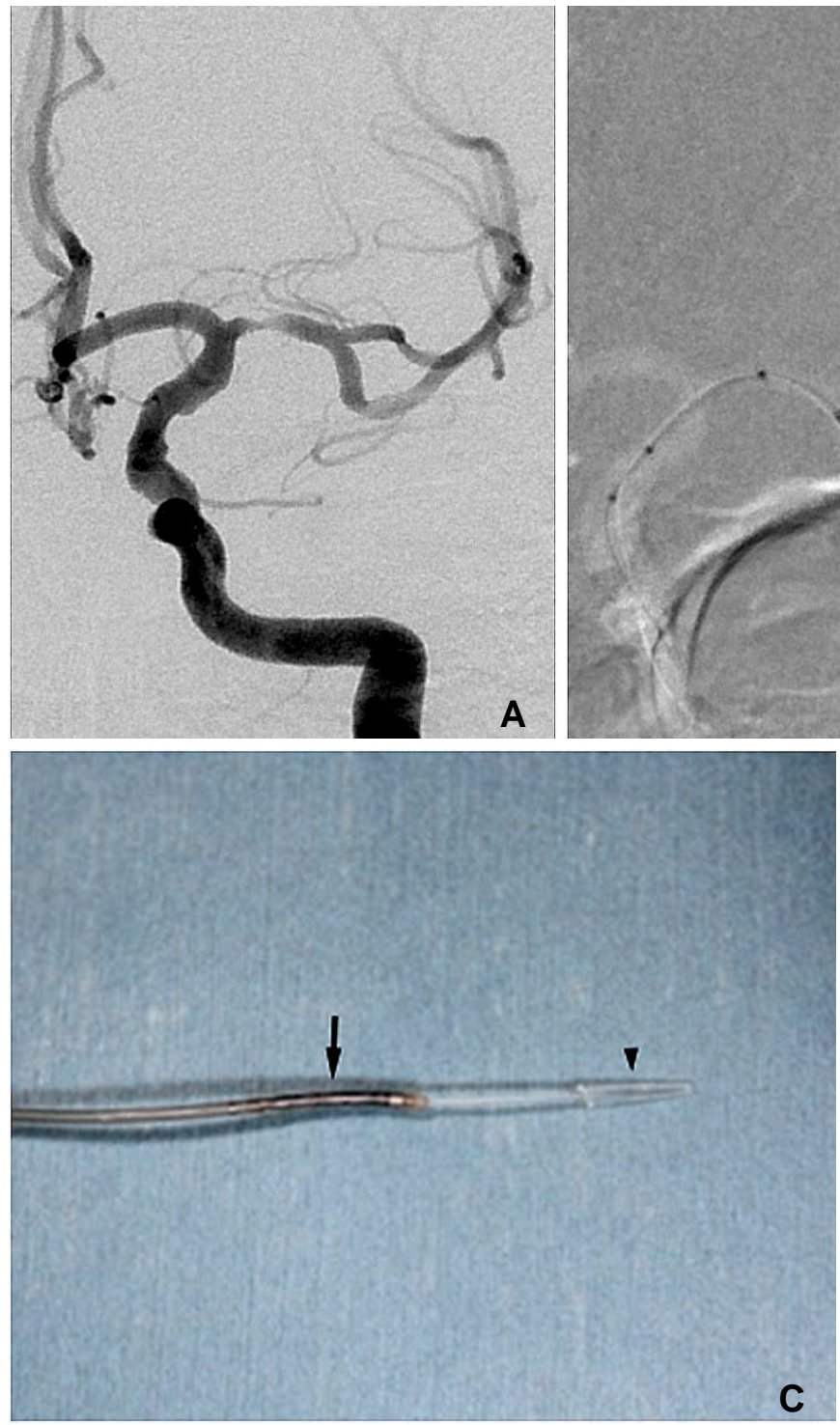
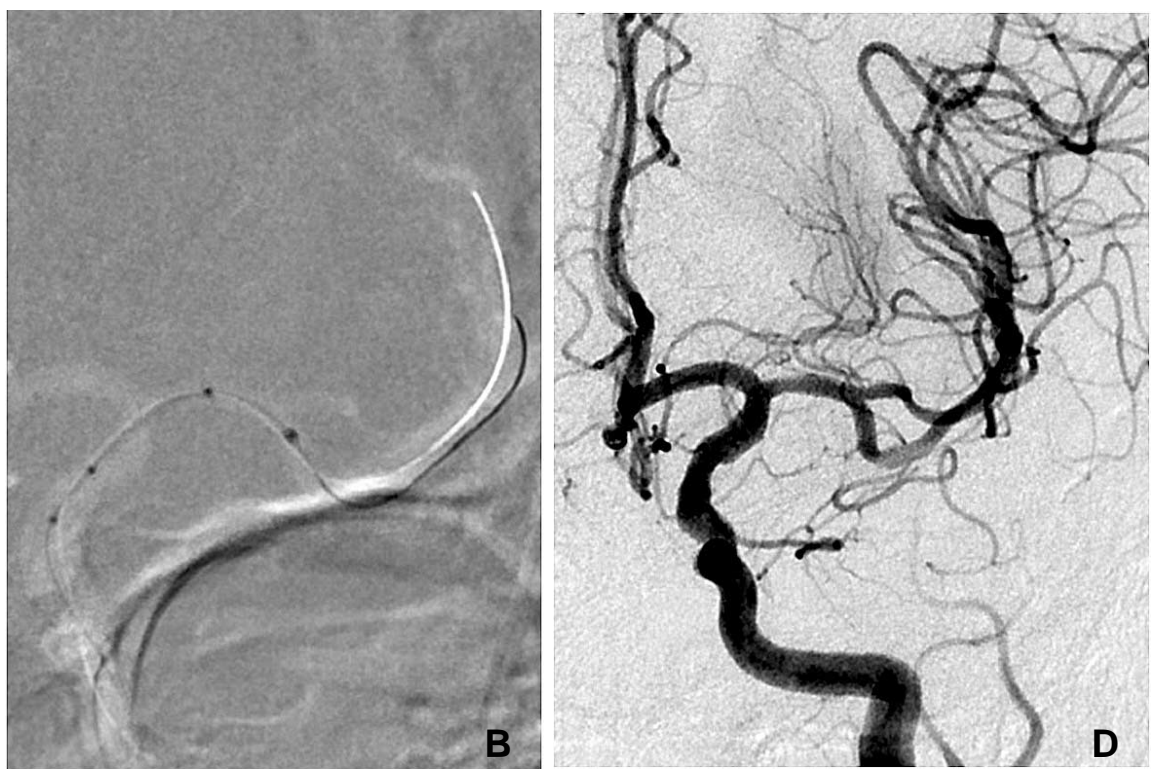

Fig. 2. A 70-year-old female presented with dysarthria and right sided weakness.

A.There was severe stenosis of right M1 and the proximal cervical internal carotid artery was tortuous (not shown).

B. Wingspan was delivered in proper position without successful deployment of the stent due to marked resistance between inner and outer body.

C. Removed system reveals stretched inner body and olive tip (arrowhead) protruded far beyond the loaded stent segment (arrow) which was not introduced at all.

D. Final angiogram obtained after Bare metal stent deployment reveals good patency of the lumen and distal branch filling. 


\section{Wingspan Deployment Failure}

outer diameter of the delivery catheter is $2.8 \mathrm{~F}$ in highflow renegade for Neuroform compared to $3.5 \mathrm{~F}$ in the outer body for Wingspan.

Although delivery failure was the main mechanism as in 3 out of our seven patients, we also met deployment or retrieval failure which has not been described in detail previously. Three stent deployment failures were related to different reasons. Two of them occurred due to proximal vessel tortuousness and the other occurred due to angled vessel configuration just distal to the stenotic lesion. Acute distal vessel angle as in M1-2 junction probably made the olive tip buckled and precluded smooth stent deployment. Two other cases revealed that the stent might not be delivered because of insufficient support of the inner body system in one and a part of the inner body had been pushed out of the delivery microcatheter (outer body) without introducing the stent segment in the other.

Retrieval failure of the olive tip did not lead to procedure failure because we could finally remove the system after resheathing the inner body by advancing the outer body over the inner body up to the olive tip. Even though this failure can be managed by resheathing technique, incomplete understanding of the stent design might result in injury of the stent vessel by forceful pulling of the system despite the resistance of the olive tip against deployed Wingspan stent. Less experience of the operators is also one reason of stent deployment failures. Lee et al. [18] reported three cases of stents misplacement in the early phase of their experience.

In conclusion, our study revealed that there were three mechanisms of technical failure in using Wingspan stent: delivery, deployment and retrieval failures. These technical failures are related to tortuousness of the proximal as well as distal cerebral vessels to the stenotic lesion, rather large and bulky profile of the olive tip, tight and rigid lumen of previously stented vessel. To avoid device-related complication, complete understanding of the stent design is mandatory before using the stent.

\section{References}

1. Suh DC, Kim JL, Kim EH, Kim JK, Shin JH, Hyun DH, et al. Carotid baroreceptor reaction after stenting in 2 locations of carotid bulb lesions of different embryologic origin. AJNR Am J Neuroradiol 2012;33:977-981

2. Suh DC, Ko YB, Park ST, Yoon KH, Lim OK, Oh JS, et al. Computational flow dynamics of the severe M1 stenosis before and after stenting. Neurointervention 2011;6:13-16

3. Lu PH, Park JW, Park S, Kim JL, Lee DH, Kwon SU, et al. Intracranial stenting of subacute symptomatic atherosclerotic occlusion versus stenosis. Stroke 2011;42:3470-3476

4. Park ST, Kim JK, Yoon KH, Park SO, Park SW, Kim JS, et al Atherosclerotic carotid stenoses of apical versus body lesions in high-risk carotid stenting patients. AJNR Am J Neuroradiol 2010;31:1106-1112

5. Suh DC, Lee SH, Kim KR, Park ST, Lim SM, Kim SJ, et al. Pattern of atherosclerotic carotid stenosis in Korean patients with stroke: different involvement of intracranial versus extracranial vessels. AJNR Am J Neuroradiol 2003;24:239-244

6. Choi JW, Kim JK, Choi BS, Lim HK, Kim SJ, Kim JS, et al. Angiographic pattern of symptomatic severe M1 stenosis: comparison with presenting symptoms, infarct patterns, perfusion status, and outcome after recanalization. Cerebrovasc Dis 2010;29:297-303

7. In HS, Lee HY, Park JY, Kim SY, Jung JH, Kim JS, et al. Intracranial stenting in patients with atherosclerotic stenosis associated with various aneurysms in the same diseased arterial segment. AJNR Am J Neuroradiol 2010;31:1895-1898

8. Suh DC, Kim JK, Choi JW, Choi BS, Pyun HW, Choi YJ, et al. Intracranial stenting of severe symptomatic intracranial stenosis: results of 100 consecutive patients. AJNR Am J Neuroradiol 2008;29:781-785

9. Pyun HW, Suh DC, Kim JK, Kim JS, Choi YJ, Kim MH, et al. Concomitant multiple revascularizations in supra-aortic arteries: short-term results in 50 patients. AJNR Am J Neuroradiol 2007;28:1895-1901

10. Suh DC, Kim EH. The therapeutic time window related to the presenting symptom pattern, that is, stable versus unstable patients, can affect the adverse event rate of intracranial stenting. Stroke 2009;40:e588-589; author reply e590

11. Bose A, Hartmann M, Henkes H, Liu HM, Teng MM, Szikora I, et al. A novel, self-expanding, nitinol stent in medically refractory intracranial atherosclerotic stenoses: the Wingspan study. Stroke 2007;38:1531-1537

12. Gao X, Liang G, Li Z, Wei X, Wang X, Zhang H, et al. Wingspan stent-assisted coiling of intracranial aneurysms with symptomatic parent artery stenosis: experience in 35 patients with mid-term follow-up results. Eur J Radiol 2012;81:e750-756

13. Chiam PT, Samuelson RM, Mocco J, Hanel RA, Siddiqui AH, Hopkins LN, et al. Navigability trumps all: stenting of acute middle cerebral artery occlusions with a new self-expandable stent. AJNR Am J Neuroradiol 2008;29:1956-1958

14. Costalat V, Maldonado IL, Vendrell JF, Riquelme C, Machi P, Arteaga $\mathrm{C}$, et al. Endovascular treatment of symptomatic intracranial stenosis with the Wingspan stent system and Gateway PTA balloon: a multicenter series of 60 patients with acute and midterm results. J Neurosurg 2011;115:686-693

15. Fiorella D, Levy EI, Turk AS, Albuquerque FC, Niemann DB, Aagaard-Kienitz B, et al. US multicenter experience with the wingspan stent system for the treatment of intracranial atheromatous disease: periprocedural results. Stroke 2007;38:881-887

16. Levy EI, Siddiqui AH, Crumlish A, Snyder KV, Hauck EF, Fiorella DJ, et al. First Food and Drug Administration-approved prospective trial of primary intracranial stenting for acute stroke: SARIS (stent-assisted recanalization in acute ischemic stroke). Stroke 2009;40:3552-3556

17. Zaidat OO, Wolfe T, Hussain SI, Lynch JR, Gupta R, Delap J, et al. Interventional acute ischemic stroke therapy with intracranial self-expanding stent. Stroke 2008;39:2392-2395 


\section{Lin-Bo Zhao, et al.}

18. Lee DH, Daza OD, Arat A, Mawad ME. The WingSpan stent system for the treatment of intracranial atherosclerotic stenoses: a single center experience. Neurointervention 2009;4:87-93

19. Suh DC, Kim SJ, Lee DH, Kim W, Choi CG, Lee JH, et al. Outcome of endovascular treatment in symptomatic intracranial vascular stenosis. Korean J Radiol 2005;6:1-7

20. Yu SC, Leung TW, Lee KT, Hui JW, Wong LK. Angioplasty and stenting of atherosclerotic middle cerebral arteries with Wingspan: evaluation of clinical outcome, restenosis, and procedure outcome.
AJNR Am J Neuroradiol 2011;32:753-758

21. Kim JK, Choi JW, Choi BS, Kim TI, Whang SM, Kim SJ, et al. Sum of the Curve Indices for Estimating the Vascular Tortuousness of the Internal Carotid Artery. Neurointervention 2009;4:101-106

22. Lesley WS, Rangaswamy R. Catheter exchange technique for the Wingspan stent: technical note. J Neurointerv Surg 2009;1:168170 